\title{
Extreme penoscrotal transposition
}

\section{Letter to the Editor}

$\mathrm{P}$ enoscrotal transposition (PST) is an extremely rare congenital malformation, usually associated with a wide variety of other anomalies. We describe an exceptional case of a newborn with extreme PST and severe hypospadias but normal upper urinary tract and no other associated malformations.

A newborn male delivered at term with no reported antenatal complications. Three routine obstetrical sonography showed normal fetal development. There was no evidence of mother being exposed to teratogens during pregnancy. On physical examination, an abnormal appearance of the external genitalia could be seen. There was a complete rotation of the external genitalia with a normal scrotum and testis but a rudimentary penis with a severe proximal hypospadias and chordee just attached anterior to the anal margin. Urinalysis, renal and vesical sonography and voiding cystourethrography showed no other urological abnormalities. There were no associated cardiological or gastrointestinal anomalies.

Complete PST is a very uncommon heterogeneous condition in which the scrotum is positioned superior and anterior to the penis. It was first recognized in 1923 by Appleby in an adult patient. ${ }^{[1,2]}$ Less than 20 cases of extreme degree of PST with normal scrotum have been reported in the literature. ${ }^{[1-7]}$ PST results from abnormal genital tubercle development around the 6th week gestation. It is associated with delay in the midline fusion of the urethral folds. Although the occurrence of most reported cases of PST has been sporadic, other congenital anomalies like hypospadias, chordee and renal agenesis or dysplasia could be found in approximately $90 \%$ of patients. ${ }^{[5]}$ Gastrointestinal abnormalities, predominantly imperforate anus were found in $30 \%$ of cases. ${ }^{[8]}$ PST may present with a broad spectrum of abnormalities ranging from simple shawl scrotum (doughnut scrotum) to very complex extreme transposition with cardiac, gastrointestinal, craniofacial, central nervous system, genital and urological malformations associated. ${ }^{[6]}$ Growth deficiency and mental retardation have also been noticed in $60 \%$ of patients. ${ }^{[9]}$ Differential diagnosis must include pseudohermaphroditism, penoscrotal hypospadias, micropenis, intrauterine penile amputation and especially penile agenesis with a midline skin tag anterior to the anus.

Surgery of the more complex cases of PST is technically challenging for pediatric surgeons. It is usually performed between 12-18 months. The size of the phallus and its potential to develop at puberty into a sexually satisfactory penis are of paramount relevance when surgery is planned. In order to assess this situation, surgeon must carefully palpate the corporal bodies to determine their bulk and sometimes perform a testosterone test to demonstrate erections. Extreme penoscrotal transposition with severe hypospadias and chordee is difficult to differentiate from penile agenesis with a midline skin tag anterior to the anus (with penile atrophic body buried in the perineum). In both cases the penile reconstruction and repositioning are often unsatisfactory, and female gender reassignment, while ethically controversial, may be a prudent therapeutic in selected cases.

Roberto Méndez-Gallart, Manuel G Tellado, Ivan Somoza Department of Pediatric Surgery

Children's Hospital "Teresa Herrera"

Complexo Hospitalario Universitario de A Coruña

As Xubias 84. 15004. A Coruña, Spain

Email: roberto.mendez.gallart@sergas.es

\section{References}

1 Avolio L, Karmarkar SJ, Martucciello G. Complete penoscrotal transposition. Urology 2006;67:1287.

2 Chadha R, Mann V, Sharma A, Bagga D. Complete penoscrotal transposition and associated malformations. Pediatr Surg Int 1999;15:505-507.

3 Cohen-Addad N, Zarafu IW, Hanna MK. Complete penoscrotal transposition. Urology 1985;26:149-152.

4 Kain R, Arulprakash S. Complete penoscrotal transposition. Indian Pediatr 2005;42:718.

5 Pinke LA, Rathbun SR, Husmann DA, Kramer SA. Penoscrotal transposition: review of 53 patients. J Urol 2001;166:1865-1868.

6 Meguid NA, Temtamy SA, Mazen I. Transposition of external genitalia and associated malformations. Clin Dysmorphol 2003;12:59-62.

7 Redman JF, Bissada NK. Complete penoscrotal transposition. Urology 2007;69:181-182.

8 Buyukkayhan D, Kurtoglu S, Koklu E, Hatipoglu N, Akcakus M. Complete penoscrotal transposition associated with aortic stenosis in a newborn. J Pediatr Endocrinol Metab 2007;20:881.

9 MacKenzie J, Chitayat D, McLorie G, Balfe JW, Pandit PB, Blecher SR. Penoscrotal transposition: a case report and review. Am J Med Genet 1994;49:103-107.

doi:10.1007/s12519-010-0014-5 